\title{
Epigenetic Study of Esophageal Carcinoma Based on Methylation, Gene Integration and Weighted Correlation Network Analysis
}

\author{
Yanzhao $\mathrm{Xu}^{\prime}$ \\ $\mathrm{Na}$ Wang $\left(\mathbb{D}^{2}\right.$ \\ Rongfeng $\mathrm{Liu}^{3}$ \\ Huilai Lv' \\ Zhenhua Li $\mathbb{D}^{\prime}$ \\ Fan Zhang' \\ Chunyue Gai' \\ Ziqiang Tian (iD) \\ 'Department of Thoracic Surgery, \\ ${ }^{2}$ Department of Cancer Institute, \\ ${ }^{3}$ Department of Oncology, The Fourth \\ Hospital of Hebei Medical University, \\ Shijiazhuang, Hebei, 0500II, People's \\ Republic of China
}

Correspondence: Ziqiang Tian Department of Thoracic Surgery, The Fourth Hospital of Hebei Medical University, No. 12, Jiankang Road, Shijiazhuang, 0500II, People's Republic of China

Email tianziqianghebei@163.com
Purpose: Esophageal carcinoma is a common and highly metastatic malignant tumor of the digestive tract. The aim of the present study was to identify potential molecular markers of esophageal carcinoma that may help its diagnosis and treatment.

Materials and Methods: First, mRNA and DNA methylation data were downloaded from The Cancer Genome Atlas (TCGA) database for the identification of differentially expressed genes (DEGs) and DNA methylation analysis. Secondly, Weighted Gene Co-Expression Network Analysis (WGCNA) was used to identify important modules and hub genes. In addition, correlation analysis between DNA methylation genes and DEGs was performed. Thirdly, the GSE45670 dataset was used to validate the expression of the diagnostic and survival ability analysis of genes in TCGA data. Finally, reverse transcription-quantitative PCR and immunohistochemical analysis of genes were performed.

Results: A total of 2408 DEGs and 5134 differentially methylated sites were obtained. In the WGCNA analysis, the royal blue module was found to be the optimal module. In addition, hub genes in the module, including ESRRG, MFSD4, CCKBR, ATP4B, ESRRB, ATP4A, CCKAR and B3GAT1, were also differentially methylated genes and DEGs. It was found that CCKAR, MFSD4 and ESRRG may be diagnostic gene biomarkers for esophageal carcinoma. In addition, the high expression of MFSD4 was significantly correlated with patient survival. Immunohistochemistry analysis results showed that the gene expression levels of ATP4B, B3GAT1, CCKBR and ESRRG were decreased in esophageal carcinoma tissues, which was in line with the bioinformatics results.

Conclusion: Therefore, these identified molecular markers may be helpful in the diagnosis and treatment of esophageal carcinoma.

Keywords: esophageal carcinoma, DNA methylation, Weighted Gene Co-Expression Network Analysis; differentially expressed genes, diagnosis, prognosis

\section{Introduction}

Esophageal carcinoma is a common type of cancer of the digestive tract with a high morbidity and mortality, and its morbidity varies significantly among different regions and ethnic groups. ${ }^{1,2}$ In China, the morbidity and mortality rates of esophageal carcinoma are higher in men than in women. ${ }^{3}$ Patients with esophageal carcinoma have no obvious symptoms in the early stage, and present with typical dysphagia in the middle and late stages. ${ }^{4}$ To date, the most common treatment for esophageal carcinoma is surgical resection. However, most patients with esophageal carcinoma are already in the middle and advanced stages of the disease upon 
admission. ${ }^{5}$ In these patients, tumor metastasis leads to the recurrence of esophageal carcinoma, ultimately resulting in the failure of surgical treatment. ${ }^{6}$

Although the specific pathological mechanisms of esophageal carcinoma are unclear, certain studies have reported various genes involved in the progression of the disease. Previous studies have found that solute carrier family 52 member 3 (SLC52A3) was up-regulated in esophagus dysplasia and esophageal squamous cell carcinoma (ESCC), and can therefore be used as a biomarker for the prediction and prognosis of esophageal carcinoma. ${ }^{7}$ The expression levels of phospholipase $\mathrm{C}$ epsilon 1 (PLCE1) and protein kinase $\mathrm{C}$ alpha (PRKCA) are upregulated in esophageal carcinoma, an increase that is significantly associated with poor prognosis. ${ }^{8}$ In addition, insulin-like growth factor binding protein like 1 (IGFBPL1) ${ }^{9}$ SHANK associated RH domain interactor

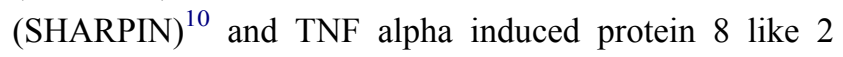
(TIPE2), ${ }^{11}$ among others, are involved in the regulatory mechanism of esophageal carcinoma.

Epigenetic modifications, such as DNA methylation, can change gene expression patterns and play an important role in cancer formation. ${ }^{12}$ DNA methylation has been extensively investigated and is used for the diagnosis and treatment of tumors. ${ }^{13}$ Abnormal hypermethylation is associated with the inactivation of tumor-related genes in multiple tumor types. ${ }^{14}$ Previous studies have reported that, compared with healthy controls, patients with esophageal carcinoma exhibit abnormal p16 gene methylation. In the case analysis based on p16 methylation, the mutation/polymorphism of p53 was found to be significantly associated with the risk of esophageal carcinoma. ${ }^{15}$ Moreover, the cyclin-dependent kinase inhibitor $2 \mathrm{~A}$ (CDKN2A) is a tumor suppressor gene that significantly increases the methylation frequency during esophageal carcinoma carcinogenesis, and may be a biomarker for the early diagnosis of esophageal carcinoma. ${ }^{16}$ In addition, one-carbon metabolism-related B vitamins may interact to affect esophageal carcinoma and dysplasia risks, since vitamin B2, B6, B12 and folate play important roles in DNA synthesis, repair and methylation. ${ }^{17}$

Therefore, analyzing the correlation between gene transcription sequencing data and DNA methylation modification data is important for elucidating the epigenetic regulation mechanism of esophageal carcinoma. In the present study, the DNA methylation and gene expression data of esophageal carcinoma were analyzed, and Weighted Gene Co-Expression Network Analysis
(WGCNA) was performed to identify important modules and hub genes. Finally, 8 candidate genes (ESRRG, MFSD4, CCKBR, ATP4B, ESRRB, ATP4A, CCKAR and B3GAT1) were identified as potential diagnostic and treatment targets in esophageal carcinoma.

\section{Materials and Methods Datasets}

In the present study, mRNA expression (IlluminaHiSeq_RNASeqV) and DNA methylation data (JHU_USC_HumanMethylation450) were downloaded from The Cancer Genome Atlas data portal (TCGA, https://tcga-data.nci.nih.gov/tcga/). The data were from primary solid tumor tissue samples of patients with esophageal carcinoma and normal tissue samples of a normal control group. The information of 185 samples was used for mRNA expression and DNA methylation data analysis. Among them, there were 170 common samples (161 cases and 9 normal controls) between mRNA expression and DNA methylation data. The clinical information of 185 patients with esophageal carcinoma from TCGA database was analyzed. Chi-square test was used to verify the significance of the difference. The results showed no significant difference in disease stage or outcome between the ESCC and esophageal adenocarcinoma (EAC) groups (Table S1). Therefore, ESCC and EAC were grouped together into a disease group for unified analysis.

\section{Differential Analysis of Genes and DNA Methylation}

The differentially expressed genes (DEGs) were screened out using the R-Bioconductor package DESeq. ${ }^{18}$ First, the genes (count $=0$ ) with a distribution of $>20 \%$ in the sample were filtered. Next, false discovery rate (FDR) $<0.05$ and | $\log 2$ FoldChange $>1$ were used to identify DEGs.

The COHCAP package in $\mathrm{R}$ was used to screen differentially methylated sites. ${ }^{19}$ The $\Delta \beta$ is the value of differentially methylated sites. First, the methylated sites without a $\beta$-value and a distribution of $>20 \%$ in the sample were filtered. Next, $\Delta \beta>0.2$ and FDR $<0.05$ were used to obtain differentially methylated sites and regions. Subsequently, a Fisher's Exact test (odds ratio $\neq 1$, and $\mathrm{P}<0.05$ or $\mathrm{P}<0.01$ ) was used for functional enrichment analysis of the genome in the differentially methylated sites. 


\section{Construction of the WGCNA Co-Expression Network}

First, the WGCNA package in R (http://www.r-project.org/ ) was used to identify significant modules and genes in esophageal carcinoma under the threshold of $\beta=5$. Next, | correlation coefficient $>0.2$ and $\mathrm{P}<0.05$ were used to explore the correlation between modules and tumorparacancer. A Fisher's Exact test $(\mathrm{P}<0.05)$ was then used for enrichment analysis, to explore the relationship between modules and DEGs. Finally, Cytoscape software (http://www.cytoscape.org) was used for the visualization of the optimal module with a threshold of $>0.1$. The selection criteria for hub genes in the optimal module was |correlation. module module| (|Cor.MM $\mid)$, which was used to rank top 10 genes.

\section{Functional Analysis of Genes in the Optimal Module}

Gene Ontology (GO) and Kyoto Encyclopedia of Genes and Genomes (KEGG) pathway analyses of genes in the optimal module were performed using the GeneCodis 4.0 (https://genecodis.genyo.es/). FDR $<0.05$ was set as the threshold of statistical significance.

\section{Correlation Analysis of DNA Methylation Genes and DEGs}

Correlation analysis between DNA methylation gene and gene expression profile was mainly to analyze the correlation between differentially methylated sites and corresponding gene expression differences. First, the up/down-regulation relationship between differentially methylated gene $\mathrm{CpG}$ islands and DEGs was integrated. Next, $\mathrm{P}<0.05$ and |correlation $\mid(\mid$ cor $\mid)>0.5$ were used to analyze the correlation between the differentially methylated sites and the DEGs. Finally, $\mathrm{P}<0.05$ was used to identify the DEGs that were significantly negatively correlated with differentially methylated regions/ sites.

\section{Expression Validation, and Diagnostic and Prognostic Analysis of Identified Genes}

The expression validation of identified genes was performed in the GSE45670 data set (involving 28 cases and 10 normal controls) which was obtained from the Gene Expression Omnibus (GEO) database. ${ }^{20}$ In addition, TCGA data were used to analyze the diagnostic and survival ability of the identified DEGs.

\section{In vitro Validation of Identified DEGs}

The detailed inclusion criteria for patients with esophageal carcinoma were as follows: (1) Patients who had received simple surgical treatment as initial treatment; (2) patients had complete preoperative imaging data of computed tomography (CT), esophagoscopy and esophagus; (3) patients were diagnosed with esophageal carcinoma by histopathological or cytological examination; (4) patients aged $\leq 80$ years (to avoid confusion with natural death); (5) patients had no history of other malignant tumors. The detailed exclusion criteria for patients with esophageal carcinoma were as follows: (1) Patients with other tumors; (2) patients did not meet the diagnostic and inclusion criteria; (3) patients had a metastatic malignant tumor of the esophagus; (4) patients presented with recurrence or received secondary treatment; (5) patients died during hospitalization or discharge within 30 days (during this period, the cause of death of patients was mostly surgical wounds, not the disease itself); (6) incomplete basic information of patients on admission; (7) patients who suffered from cognitive impairment and multiple organ failure.

According to the above criteria for esophageal carcinoma, 6 patients with esophageal carcinoma were selected for the present study. The tumor and adjacent normal tissue samples were subjected to reverse transcription-quantitative PCR (RT-qPCR). Total RNA was extracted using a TRIzol (tissue sample) kit (Invitrogen; Thermo Fisher Scientific, Inc.). A FastQuant cDNA synthesis kit (KR106; Tiangen Biotech Co., Ltd.) was used for mRNA reverse transcription. RT-qPCR was performed using SuperReal PreMix Plus (SYBR Green), which was carried out using SuperReal reagent (FP205; Tiangen Biotech Co., Ltd.) manual. Each experiment was repeated three times. Glyceraldehyde3-phosphate dehydrogenase (GAPDH) and actin beta (ACTB) were used as internal control for gene detection. The gene expression levels were calculated as fold-changes using the $2^{-\Delta \Delta \mathrm{Ct}}$ method. $^{21}$

All experimental procedures were approved by the Clinical Research Ethics Committee of The Fourth Hospital of Hebei Medical University (NO.2020KY183). All participants were informed as to the purpose of this study, and that this study complied with the Declaration of Helsinki.

\section{Immunohistochemical Analysis}

Tumor and adjacent normal tissue samples were obtained for immunohistochemical analysis. A total of 4 genes 
(ATP4B, B3GAT1, CCKBR and ESRRG) were randomly selected from the candidate genes for validation. Immunohistochemistry was performed using the streptavidin-peroxidase (SP) method. Paraffin sections of tissue samples $(4 \mu \mathrm{m})$ were dewaxed routinely and washed with phosphate-buffered saline (PBS) for three times $(5 \mathrm{~min} /$ time). These sections were repaired with $\mathrm{pH} 6.0$ citric acid at high pressure for $3 \mathrm{~min}$, kept warm for $30 \mathrm{~min}$ and cooled to room temperature, and then washed with PBS three times ( $5 \mathrm{~min} /$ time). The slides were immersed in $3 \% \mathrm{H} 2 \mathrm{O} 2$ for $30 \mathrm{~min}$ to block endogenous peroxidase activity and were then washed with PBS three times (5 $\mathrm{min} /$ time). The slides were sealed with goat serum for 30 min to block natural or impure antibodies. After adding the primary antibodies (ATP4B, B3GAT1, CCKBR and ESRRG), the slides were incubated overnight at $4^{\circ} \mathrm{C}$, washed and rewarmed for $30 \mathrm{~min}$ for the next day, washed with PBS three times ( $5 \mathrm{~min} / \mathrm{time})$. The secondary antibody was added dropwise and the sections were incubation at room temperature for $30 \mathrm{~min}$, and washed with PBS three times (5 min/time). Finally, 3,3'diaminobenzidine (DAB) staining, hematoxylin restaining and microscopic observation were performed. Brown-yellow coloring was defined as positive expression.

\section{Statistical Analysis}

All statistical analysis was performed using GraphPad Prism (GraphPad Software, Inc.). For the RT-qPCR verification assay, one-way analysis of variance method was used to statistically analyze the difference in gene expression. $\mathrm{P}<0.05$ was considered to indicate a statistically significant difference. All analyses were repeated at least three times independently.

\section{Results}

\section{Identification of DEGs and DNA Methylation Analysis}

According to the screening criteria of $\mathrm{FDR}<0.05$ and | log2FoldChange $>1$, a total of 2408 DEGs were obtained. Among them, 1311 were up-regulated and 1097 were down-regulated. The top 10 up-regulated genes were MMP11, TPX2, ESM1, BIRC5, NUF2, TDO2, KIF18A, KIF23, NEK2 and UBE2T. The top 10 down-regulated genes were TMED6, AQP4, PGA3, SIGLEC11, CKMT2, GPR155, CKM, ESRRB, STX12 and SLC1A2.
Following the pre-treatment of methylation chip data without a $\beta$-value, 395,516 sites were obtained. A total of 5134 differentially methylated sites (4151 hypermethylated and 983 hypomethylated sites) were obtained under the screening criteria of $\Delta \beta>0.2$ and $F D R<0.05$. The Manhattan figure and volcano map of these differentially methylated sites are presented in Figure 1. The heatmap of the top 200 differentially methylated sites in terms of tumor stage, histological diagnosis and sex is shown in Figure 2. The enrichment results of genomic features of differentially methylated sites are shown in Table 1. In addition, 2940 differentially methylated $\mathrm{CpG}$ islands were obtained using $\Delta \beta>0.2$ and $\mathrm{FDR}<0.05$. Among them, there were 2637 hypermethylation and 303 hypomethylation regions.

\section{Analysis of the WGCNA Co-Expression Network}

A total of 49 modules were identified by WGCNA coexpression network analysis ( $\beta=5$; Figure 3 ). According to the correlation analysis between modules and tumorparacancer, modules and DEGs, the royal blue module was identified as the optimal module (Tables 2 and 3). The visualization of the royal blue module, which consisted of 88 nodes, 1211 edges and 10 hubs, is shown in Figure 4 . The details of these 10 hub genes are shown in the Table 4.

\section{Functional Analysis of Genes in the Royal Blue Module}

According to KEGG enrichment analysis, "gastric acid secretion" and "protein digestion and absorption" were the only two significantly enriched signaling pathways (Table S2). In addition, on the basis of GO enrichment analysis (Tables S3-S5), "ion transport" and "transmembrane transport" were the significantly enriched biological processes; "integral component of membrane" and "membrane" were the significantly enriched cellular components; "voltage-gated ion channel activity" and "chloride channel activity" were the significantly enriched molecular functions.

\section{Correlation Analysis of DNA Methylation Genes and DEGs}

A total of 97 differentially methylated regionsdifferentially expressed genes relationship pairs (DMRsDEGs, involving 85 DEGs) were identified, which included 96 pairs of hypermethylated and down-regulated 

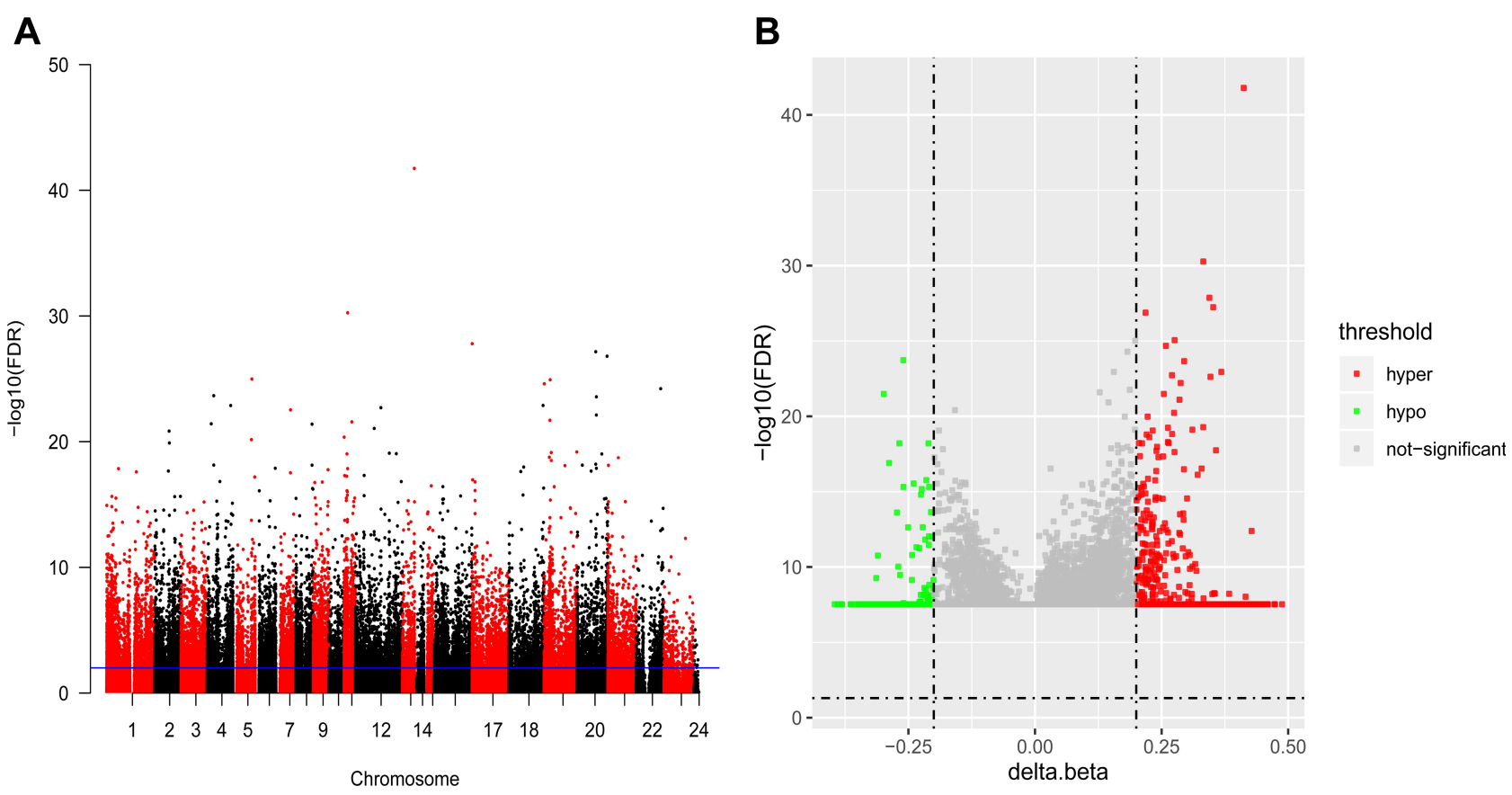

Figure I Manhattan figure and volcano map of differentially methylated sites. (A) Manhattan figure of differentially methylated sites in the chromosome. The X-axis and Y-axis represent the chromosome and the -log 10 (FDR) of differentially methylated sites, respectively. (B) Volcano map of differentially methylated sites. The X-axis and Y-axis represents $\Delta \beta$ and -logl0 (FDR), respectively. Green represent hypomethylation and and red represent hypermethylation. FDR, false discovery rate.

genes and 1 pair of hypomethylated and up-regulated genes. Based on correlation analysis $(|\operatorname{cor}|>0.5, \mathrm{P}<0.05)$, 57 pairs of differentially methylated sites-DEGs (19 positive correlation and 38 negative correlation) were obtained (Table 5). The enrichment results of the above 85 DEGs in modules is presented in Table 6 . The results showed that these DEGs were significantly enriched in the royal blue, yellow and turquoise modules $(\mathrm{P}<0.05)$. Moreover, it was found that ESRRG, MFSD4, CCKBR, ATP4B, ESRRB, ATP4A, CCKAR and B3GAT1 in hubs were also differentially methylated genes and DEGs.

\section{Expression Verification, and Diagnostic and Prognostic Analysis}

ATP4A, ATP4B, CCKAR, MFSD4 and ESRRG were randomly selected for expression verification (Figure 5). The expression levels of all aforementioned genes, except CCKAR, were down-regulated in esophageal carcinoma tissues. Among them, MFSD4 and ESRRG were the most significantly down-regulated $(\mathrm{P}<0.05)$. Simultaneously, diagnostic and prognostic analysis of these genes was performed (Figure 6). In the receiver operating characteristic (ROC) curve analysis, the area under curve (AUC) of ATP4A, ATP4B, CCKAR, MFSD4 and ESRRG was $0.605,0.645,0.805,0.761$ and 0.747 , respectively
(Figure 6A-E). It was indicated that the CCKAR, MFSD4 and ESRRG genes may be potential biomarkers for the diagnosis of esophageal carcinoma. Of note, the high expression of MFSD4 was found to have a prognostic value (Figure 6F), which showed that MFSD4 was significantly actively correlated with survival.

\section{RT-qPCR Verification}

The clinical information of enrolled individuals is presented in Table 7. GPR155, ESRRB, ESRRG, CCKAR, MMP11, TPX2, BIRC5, NUF2 and ANO1 were the top-ranking or reported genes selected for RT-qPCR verification. Among them, GPR155 (hypermethylated), ESRRB (hypomethylated), ESRRG (hypermethylated), CCKAR (hypermethylated) and MMP11 (hypermethylated) were differentially methylated genes, while TPX2, BIRC5, NUF2 and ANO1 were DEGs. All primers used are shown in Table 8 . The results showed that MMP11, TPX2, BIRC5, NUF2 and ANO1 were up-regulated and ESRRG down-regulated (Figure 7), which was consistent with the results of the bioinformatics analysis. However, the results regarding GPR155, ESRRB and CCKAR were in contrast with those of the bioinformatics analysis. The small sample size may account for the inconsistent results, and so, further research is required. 


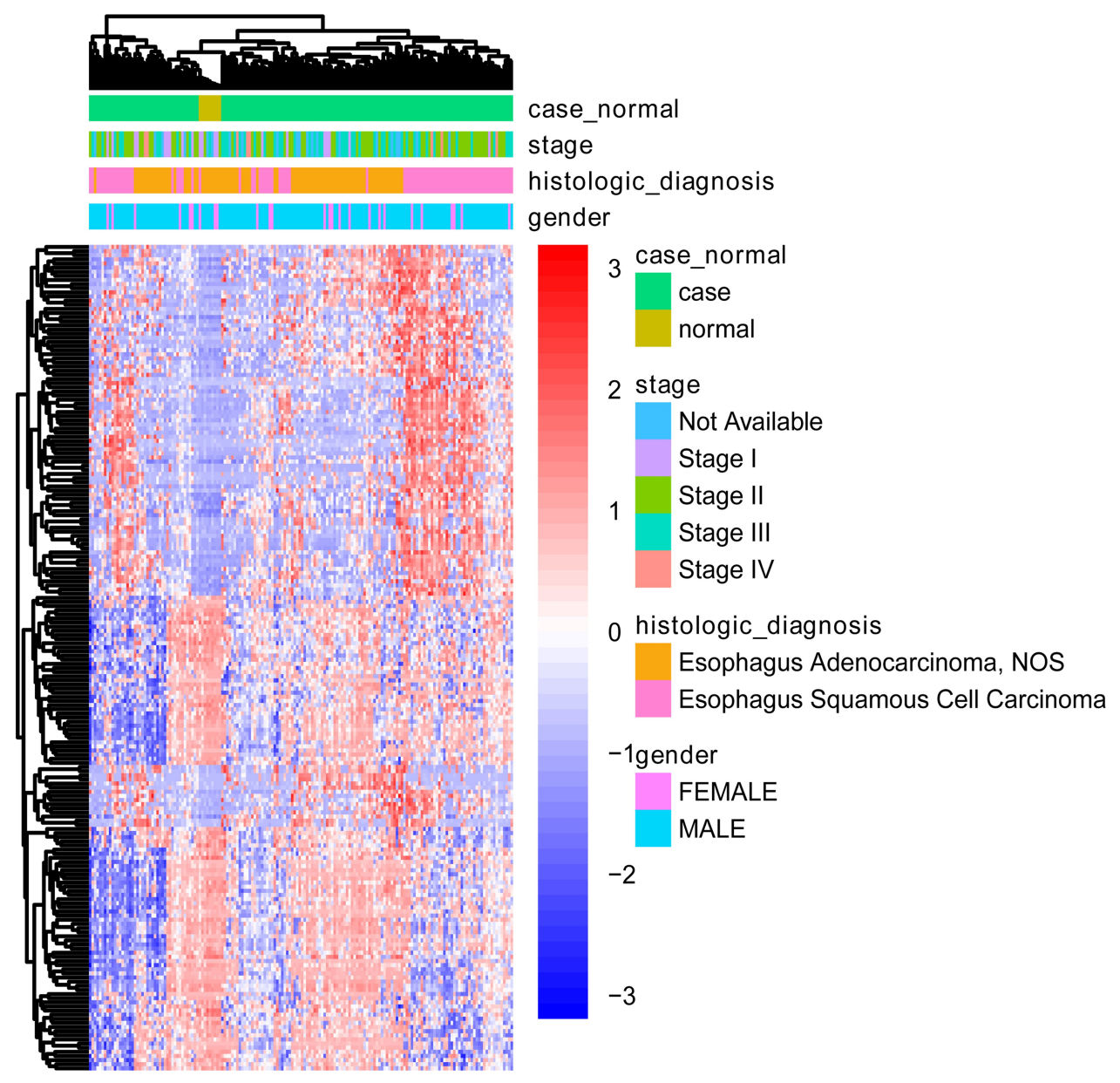

Figure 2 Heat map of the top 200 differentially methylated sites in terms of tumor stage, histologic diagnosis and sex. The figure shows the two-way hierarchical clustering results of the top 200 differentially methylated sites and samples. The clustering is constructed using the full chain method together with the Euclidean distance. Each row and column represents a differentially methylated sites and a sample, respectively. Differentially methylated sites clustering tree is shown on the right. Red indicates below the reference channel. Blue indicates the above reference.

Immunohistochemical Analysis of ATP4B, B3GATI, CCKBR and ESRRG

During immunohistochemistry, cytoplasmic staining was observed in cells with positive staining. In addition, the gene expression of ATP4B, B3GAT1, CCKBR and ESRRG was negatively correlated with the occurrence and development of esophageal carcinoma. The number and degree of cells staining positive for ATP4B, B3GAT1, CCKBR and ESRRG genes

Table I Enrichment Results of Genomic Features of Differentially Methylated Sites

\begin{tabular}{|l|c|c|c|c|c|}
\hline Feature & Genomic Context & Odds Ratio & 95\% Cl_Lower & 95\% Cl_Upper & P value \\
\hline Gene feature & TSS200 & 1.308234 & 1.22967 & 1.391213 & $3.26 \mathrm{E}-17$ \\
& TSSI500 & 1.308234 & 1.22967 & 1.391213 & $3.26 \mathrm{E}-17$ \\
& $3^{\prime}$ UTR & 1.308234 & 1.22967 & 1.391213 & $3.26 \mathrm{E}-17$ \\
& 5'UTR & 1.308234 & 1.22967 & 1.391213 & $3.26 \mathrm{E}-17$ \\
& IstExon & 1.308234 & 1.22967 & 1.391213 & $3.26 \mathrm{E}-17$ \\
& Body & 1.308234 & 1.22967 & 1.391213 & $3.26 \mathrm{E}-17$ \\
\hline \multirow{2}{*}{ CpG island (CGI) feature } & Island & 0.525387 & 0.489485 & 0.563533 & $3.54 \mathrm{E}-82$ \\
& Shelf & 1.032788 & 0.940418 & 1.132242 & 0.491955 \\
& Shore & 1.308234 & 1.22967 & 1.391213 & $3.26 \mathrm{E}-17$ \\
\hline
\end{tabular}

Abbreviations: $\mathrm{Cl}$, confidential interval; TSS, transcriptional start site. 


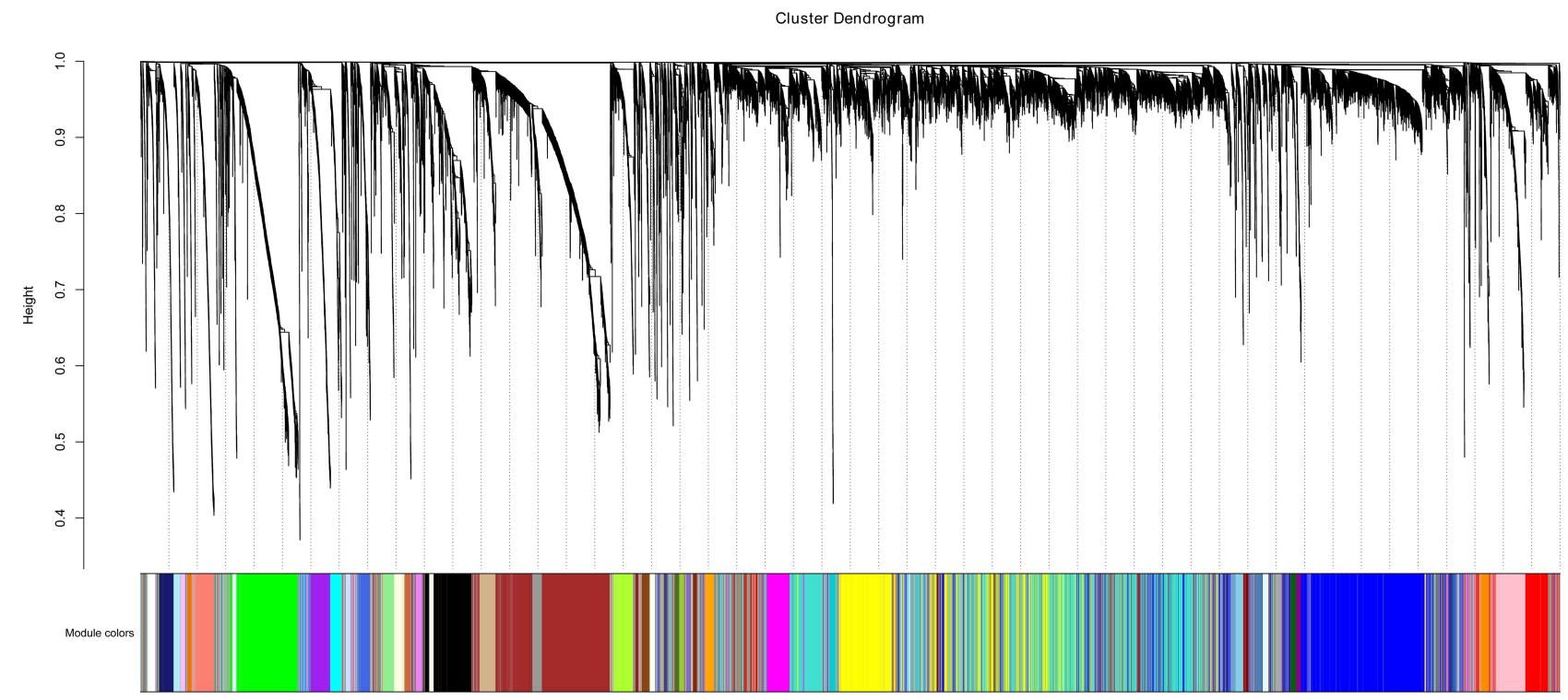

Figure 3 Clustering results of mRNA modules according to WGCNA analysis. The genes in the modules were marked with different colors, and the lower panel presents the color assigned to each module. WGCNA, Weighted Gene Co-Expression Network Analysis.

were significantly reduced in esophageal carcinoma tissues compared with adjacent normal tissues (Figure 8).

\section{Discussion}

ATPase $\mathrm{H}^{+} / \mathrm{K}^{+}$transporting subunit alpha (ATP4A) encodes $\mathrm{H}^{+}, \mathrm{K}^{+}$-ATPase which plays an essential role in the secretion of gastric acid. ${ }^{22}$ Previous studies have shown that ATP4A is associated with atypical familial type I gastric neuroendocrine tumors. ${ }^{23}$ A homozygous missense mutation in the 14th exon of the ATP4A gene triggers changes in the transmembrane region and prevents the release of protons from cells to the stomach, causing a lack of stomach acid. ${ }^{23}$ ATP4A is completely or partially methylated in tumor tissues. Following the use of a demethylating agent, the expression of ATP4A can be

Table 2 Correlation Analysis Results Between the Modules and Tumor-Paracancer

\begin{tabular}{|l|c|c|}
\hline Module & Coefficient & P value \\
\hline Royalblue & -0.63 & $2.80 \mathrm{E}-20$ \\
Violet & 0.26 & 0.00053 \\
Diumpurple3 & 0.21 & 0.0059 \\
Darkolivegreen & 0.33 & $9.50 \mathrm{E}-06$ \\
Yellow & 0.39 & $1.10 \mathrm{E}-07$ \\
Darkturquoise & 0.26 & 0.00053 \\
Turquoise & 0.34 & $4.90 \mathrm{E}-06$ \\
Darkred & 0.27 & 0.00032 \\
Grey & 0.34 & $7.80 \mathrm{E}-06$ \\
\hline
\end{tabular}

reactivated to inhibit the occurrence of gastric tumors. ${ }^{24}$ In addition, ATP4A was identified as a significant gene associated with Barrett's esophagus. ${ }^{25}$ ATPase $\mathrm{H}^{+} / \mathrm{K}^{+}$transporting subunit beta (ATP4B) is an important tumor suppressor gene, whose down-regulation is associated with gastric cancer. ${ }^{22,26}$ A notable consistency was identified between the downregulated and methylated states of ATP4B and ATP4A in gastric cancer tissues. ${ }^{22}$ These studies indicated that ATP4A and ATP4B play an important role in the inhibition of cancer. In the present study, ATP4A and ATP4B were down-regulated and hypomethylated in esophageal carcinoma tissues. Therefore, we hypothesized that the down-regulation of ATP4A and ATP4B may be associated with DNA methylation. This further suggested that epigenetic changes of ATP4A and ATP4B may play an essential role in esophageal carcinoma.

Cholecystokinin A receptor (CCKAR) is a G proteincoupled receptor that can be activated by cholecystokinin

Table 3 Enrichment of Modules in DEGs

\begin{tabular}{|l|c|c|c|c|}
\hline Module & $\begin{array}{c}\text { Odds } \\
\text { Ratio }\end{array}$ & $\begin{array}{c}\mathbf{9 5 \%} \\
\text { CI_Lower }\end{array}$ & $\begin{array}{c}\mathbf{9 5 \%} \\
\text { CI_Upper }\end{array}$ & P value \\
\hline Royalblue & 1115.129 & 192.8794 & $4.5 \mathrm{E}+15$ & $4.54 \mathrm{E}-138$ \\
Violet & 2.735852 & 1.720684 & 4.253173 & $2.30 \mathrm{E}-05$ \\
Yellow & 0.357309 & 0.279922 & 0.45057 & $1.26 \mathrm{E}-23$ \\
Turquoise & 0.494915 & $0.42208 \mathrm{I}$ & 0.577697 & $3.60 \mathrm{E}-22$ \\
Darkred & 0.083847 & 0.010054 & 0.308444 & $9.07 \mathrm{E}-08$ \\
\hline
\end{tabular}

Abbreviation: $\mathrm{Cl}$, confidence interval. 


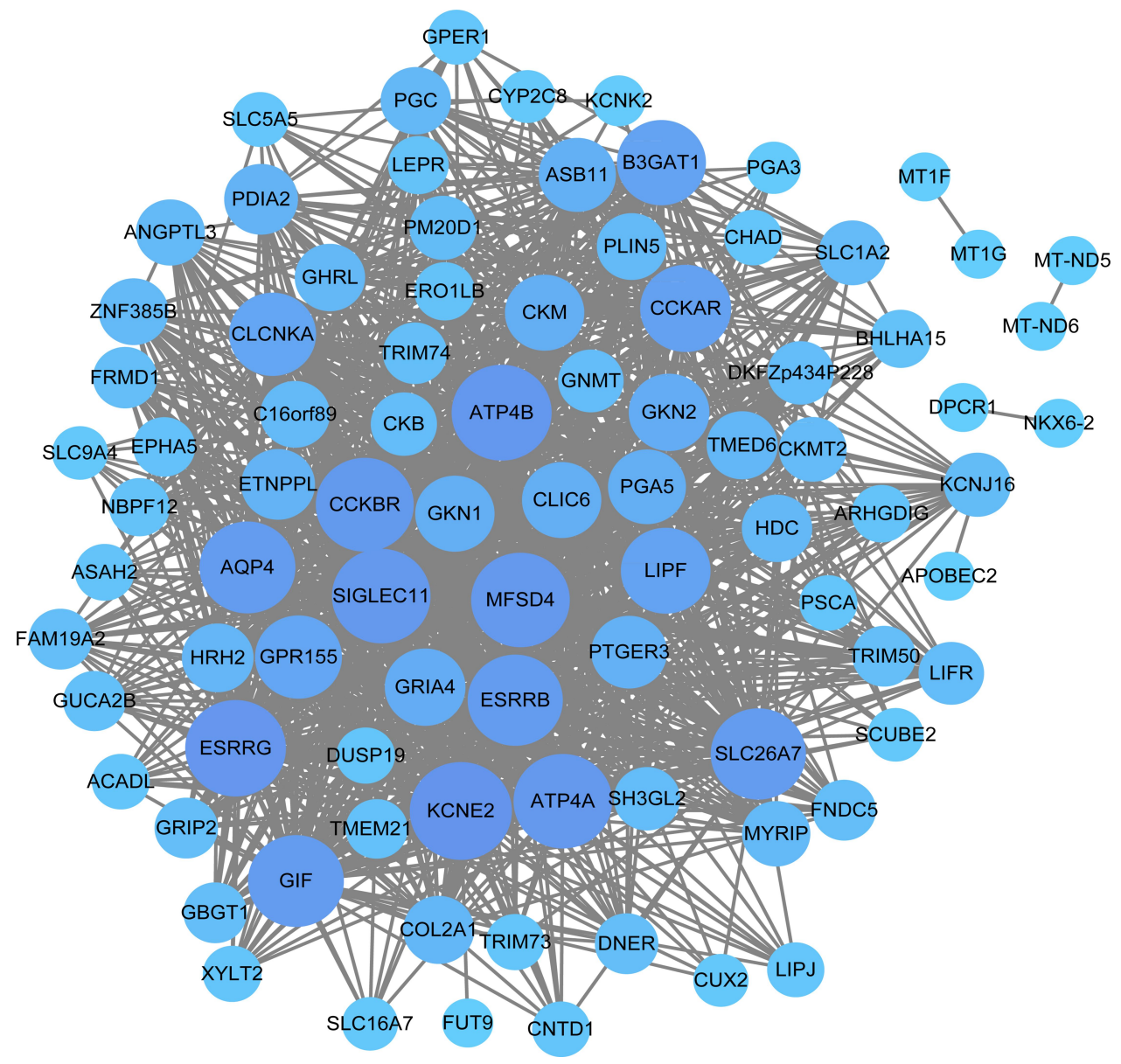

Figure 4 Visualization of the royal blue module in the WGCNA co-expression network. The circle and gray edge line represents the genes in the modules and the edge, respectively. The larger circle represent the hub genes. WGCNA, Weighted Gene Co-Expression Network Analysis.

(CCK), whose mutation can affect the risk of gallbladder cancer in women. ${ }^{27}$ Previous studies have found that the expression level of CCKAR in a gallbladder with gallstones was significantly lower than that in a gallbladder without gallstones. ${ }^{28}$ In addition, CCKAR has been found to be associated with tumor suppression and is used as

Table 4 Details of Hub Genes in the Royal Blue Module

\begin{tabular}{|l|l|c|c|}
\hline Hubs & Module & Coefficient & P value \\
\hline KCNE2 & Royalblue & 0.968426 & $2.34996 \mathrm{E}-13$ \\
ESRRG & Royalblue & $0.96807 \mathrm{I}$ & $2.59365 \mathrm{E}-16$ \\
MFSD4 & Royalblue & $0.9568 I I$ & $2.35772 \mathrm{E}-15$ \\
CCKBR & Royalblue & 0.950419 & $1.07104 \mathrm{E}-10$ \\
ATP4B & Royalblue & 0.944469 & $2.41009 \mathrm{E}-17$ \\
SIGLECII & Royalblue & 0.944115 & $7.91562 \mathrm{E}-23$ \\
ESRRB & Royalblue & 0.93753 & $7.82567 \mathrm{E}-2 \mathrm{I}$ \\
ATP4A & Royalblue & 0.936846 & $4.9997 \mathrm{E}-18$ \\
CCKAR & Royalblue & 0.911212 & $2.05779 \mathrm{E}-08$ \\
B3GATI & Royalblue & 0.910831 & $1.56673 \mathrm{E}-15$ \\
\hline
\end{tabular}

a candidate gene for studying ESCC. ${ }^{29}$ The expression level of CCKBR is decreased in breast cancer. A higher protein expression of CCKBR is found in gastric cancer tissue compared with normal mucosal tissue. ${ }^{30}$ In addition, CCKAR and CCKBR have been shown to be up-regulated and down-regulated, respectively, in pancreatic cancer, suggesting that CCKAR and CCKBR may play different roles in different cancer types. ${ }^{31}$ In the present study, CCKAR and CCKBR were down-regulated in esophageal carcinoma. In addition, CCKAR and CCKBR were hypermethylated and hypomethylated, respectively. We therefore hypothesized that the down-regulation of CCKAR and CCKBR may be associated with DNA methylation. This further suggested that epigenetic changes in CCKAR and CCKBR may play an essential role in esophageal carcinoma.

The expression level of major facilitator superfamily domain containing 4A (MFSD4) mRNA is lower in gastric cancer tissues than that in the paracancerous tissues. ${ }^{32}$ 
Table 5 Correlation Analysis Between Differential Methylated Sites and DEGs

\begin{tabular}{|c|c|c|c|}
\hline Gene & Site ID & Correlation & $P$ value \\
\hline B4GALNTI & $\operatorname{cg} 0|723| 48$ & 0.586028 & $4.65 \mathrm{E}-17$ \\
\hline B4GALNTI & $\operatorname{cg} \mid 2230728$ & 0.558113 & $2.64 \mathrm{E}-15$ \\
\hline B4GALNTI & $\operatorname{cg} 25392692$ & 0.580127 & $1.13 \mathrm{E}-16$ \\
\hline DLXI & $\operatorname{cg} 01244270$ & 0.519615 & $3.85 \mathrm{E}-13$ \\
\hline DLXI & $\operatorname{cg} 15552158$ & 0.503489 & $2.59 \mathrm{E}-12$ \\
\hline FBP2 & cg01 I9783 I & -0.60906 & $1.23 \mathrm{E}-18$ \\
\hline FBP2 & cg20356482 & -0.56327 & I.29E-I5 \\
\hline GPT & $c g 11617144$ & -0.51193 & $9.68 \mathrm{E}-13$ \\
\hline GPT2 & cg0538092I & -0.52082 & $3.32 \mathrm{E}-13$ \\
\hline HOXDIO & $\operatorname{cg} 06005169$ & 0.590076 & 3.87E-17 \\
\hline HOXD9 & $\operatorname{cg}|3| 5848 \mid$ & 0.51537 & $6.42 \mathrm{E}-13$ \\
\hline HYALI & $\operatorname{cg} 06360465$ & -0.567 & $7.59 \mathrm{E}-16$ \\
\hline HYALI & cg 10580282 & -0.50645 & $1.84 \mathrm{E}-12$ \\
\hline HYALI & cg 12930727 & -0.65804 & $1.85 \mathrm{E}-22$ \\
\hline HYALI & cg|4943722 & -0.56014 & $1.99 \mathrm{E}-15$ \\
\hline IGFBP2 & cg23059946 & -0.55095 & $7.00 \mathrm{E}-15$ \\
\hline IQGAP2 & $\operatorname{cg} 08356262$ & $-0.6425 \mathrm{I}$ & $3.58 \mathrm{E}-21$ \\
\hline KALRN & $\operatorname{cg} 21425296$ & -0.58269 & $7.69 \mathrm{E}-17$ \\
\hline KCNQI & $\operatorname{cg} 02180189$ & -0.54064 & $2.74 \mathrm{E}-14$ \\
\hline LRRC2 & $\operatorname{cg}|003| 65 \mid$ & -0.52858 & $1.28 \mathrm{E}-13$ \\
\hline MAPKI2 & $\operatorname{cg} \mid 3963658$ & 0.562568 & $1.42 \mathrm{E}-15$ \\
\hline ME3 & cg02493602 & -0.69321 & I.13E-25 \\
\hline ME3 & cg|488329| & -0.69388 & $9.67 \mathrm{E}-26$ \\
\hline ME3 & cg15698545 & -0.70097 & $1.90 \mathrm{E}-26$ \\
\hline MECOM & cg00024967 & -0.63607 & I.16E-20 \\
\hline MECOM & $\operatorname{cg} 00988247$ & -0.58743 & $3.76 \mathrm{E}-17$ \\
\hline MECOM & cg0I 277372 & -0.57962 & $1.22 \mathrm{E}-16$ \\
\hline MECOM & cg03679456 & -0.59565 & $1.06 \mathrm{E}-17$ \\
\hline MECOM & $\operatorname{cg} 06201393$ & -0.52954 & $1.13 \mathrm{E}-13$ \\
\hline MECOM & cg20096204 & -0.55583 & $3.61 \mathrm{IE}-15$ \\
\hline MFSD7 & cg02096793 & -0.50801 & $1.54 \mathrm{E}-12$ \\
\hline MFSD7 & $\operatorname{cg}|365683|$ & -0.52078 & $3.34 \mathrm{E}-13$ \\
\hline MFSD7 & cgl 7952262 & -0.53049 & $1.00 \mathrm{E}-13$ \\
\hline MKRN3 & cg002I5587 & $-0.824 I$ & $2.52 \mathrm{E}-43$ \\
\hline MKRN3 & cg05952543 & -0.65901 & I.53E-22 \\
\hline MKRN3 & cgll 100640 & -0.83807 & 4.5 IE-46 \\
\hline MKRN3 & cg23234999 & -0.81036 & $7.52 \mathrm{E}-4 \mathrm{I}$ \\
\hline NXPH4 & cg087IIII75 & 0.561717 & $1.60 \mathrm{E}-15$ \\
\hline PHYHDI & cg|4299940 & -0.54099 & $2.62 \mathrm{E}-14$ \\
\hline POU6F2 & $\operatorname{cg} 03962846$ & -0.60838 & I.37E- 18 \\
\hline PRDMI6 & $\operatorname{cg}|838| 05 \mid$ & -0.53476 & $5.84 \mathrm{E}-14$ \\
\hline PTPRN2 & cg038992I5 & 0.605294 & $2.27 \mathrm{E}-18$ \\
\hline PTPRN2 & cg04237822 & 0.537075 & $4.34 \mathrm{E}-14$ \\
\hline PTPRN2 & $\operatorname{cg} 064 \mid 3087$ & 0.574856 & $2.45 \mathrm{E}-16$ \\
\hline PTPRN2 & cg085।4594 & 0.568674 & $5.98 \mathrm{E}-16$ \\
\hline PTPRN2 & cg10288307 & 0.50932 & $1.32 \mathrm{E}-12$ \\
\hline PTPRN2 & $\operatorname{cg} 10879854$ & 0.53169 & $8.63 \mathrm{E}-14$ \\
\hline PTPRN2 & $c g 11111139$ & 0.591528 & $2.00 \mathrm{E}-17$ \\
\hline PTPRN2 & $\operatorname{cg} 27096 \mid 72$ & 0.525207 & $1.94 \mathrm{E}-13$ \\
\hline RORC & $\operatorname{cg}|8| 49207$ & -0.60897 & $1.25 \mathrm{E}-18$ \\
\hline
\end{tabular}

(Continued)
Table 5 (Continued).

\begin{tabular}{|l|c|c|c|}
\hline Gene & Site ID & Correlation & P value \\
\hline RPH3AL & $\operatorname{cg} 18222500$ & 0.69607 & $5.88 \mathrm{E}-26$ \\
SAMDI3 & $\operatorname{cg} 03204322$ & -0.55147 & $6.52 \mathrm{E}-15$ \\
SELENBPI & $\operatorname{cg} \mid 8515587$ & -0.5324 & $7.88 \mathrm{E}-14$ \\
TMEM220 & $\operatorname{cg} 26234644$ & -0.53839 & $3.67 \mathrm{E}-14$ \\
VAXI & $\operatorname{cg} 03851159$ & 0.568126 & $6.47 \mathrm{E}-16$ \\
VSIG2 & $\operatorname{cg} 02082342$ & -0.63226 & $2.31 \mathrm{E}-20$ \\
VSIG2 & $\operatorname{cg} 23730696$ & -0.70122 & $1.79 \mathrm{E}-26$ \\
\hline
\end{tabular}

Table 6 Enrichment of Differentially Methylated and DEGs in Modules

\begin{tabular}{|l|c|c|c|c|}
\hline Module & $\begin{array}{c}\text { Odds } \\
\text { Ratio }\end{array}$ & $\begin{array}{c}\mathbf{9 5 \%} \\
\text { CI_Lower }\end{array}$ & $\begin{array}{c}\mathbf{9 5 \%} \\
\text { Cl_Upper }\end{array}$ & P value \\
\hline Royalblue & 18.01649 & 8.445462 & 35.03891 & I.97E-10 \\
Violet & 0 & 0 & 7.914082 & $\mathrm{I}$ \\
Diumpurple3 & 0 & 0 & Inf & $\mathrm{I}$ \\
Darkolivegreen & 0 & 0 & 8.075999 & $\mathrm{I}$ \\
Yellow & 0 & 0 & 0.510528 & 0.001837 \\
Darkturquoise & 0 & 0 & 5.941329 & $\mathrm{I}$ \\
Turquoise & 0.147352 & 0.017565 & 0.549924 & 0.000464 \\
Darkred & 0 & 0 & $5.1271 \mathrm{I}$ & $\mathrm{I}$ \\
Grey & 0.985924 & 0.383056 & 2.134444 & $\mathrm{I}$ \\
\hline
\end{tabular}

Abbreviation: $\mathrm{Cl}$, confidence interval.

Furthermore, the hypermethylation of the MFSD4 promoter was detected in cells with a low MFSD4 expression. ${ }^{32}$ In the present study, MFSD4 was down-regulated and hypermethylated, which suggested that the downregulation of MFSD4 may be associated with hypermethylation. Beta-1, 3-glucuronyltransferase 1 (B3GAT1), also known as CD57 or HNK1, which have found frequent losses in ESCC cells. ${ }^{33}$ Previous studies have reported high B3GAT1 expression in benign prostate tissue, prostate intraepithelial neoplasia and early low-grade prostate cancer. ${ }^{34}$ However, as the tumor grows, the expression of B3GAT1 gradually and locally disappears. ${ }^{34}$ In addition, the expression level of B3GAT1 is reduced in the $\mathrm{T}$ lymphocytes of patients with chronic fatigue syndrome and the brains of patients with Alzheimer's disease. ${ }^{35,36}$ In the present study, B3GAT1 was down-regulated and hypomethylated in esophageal carcinoma tissues. We hypothesized that the down-regulation of B3GAT1 was associated with DNA methylation. In conclusion, we proposed that epigenetic modifications of MFSD4 and B3GAT1 play an important role in the pathology of esophageal carcinoma. 

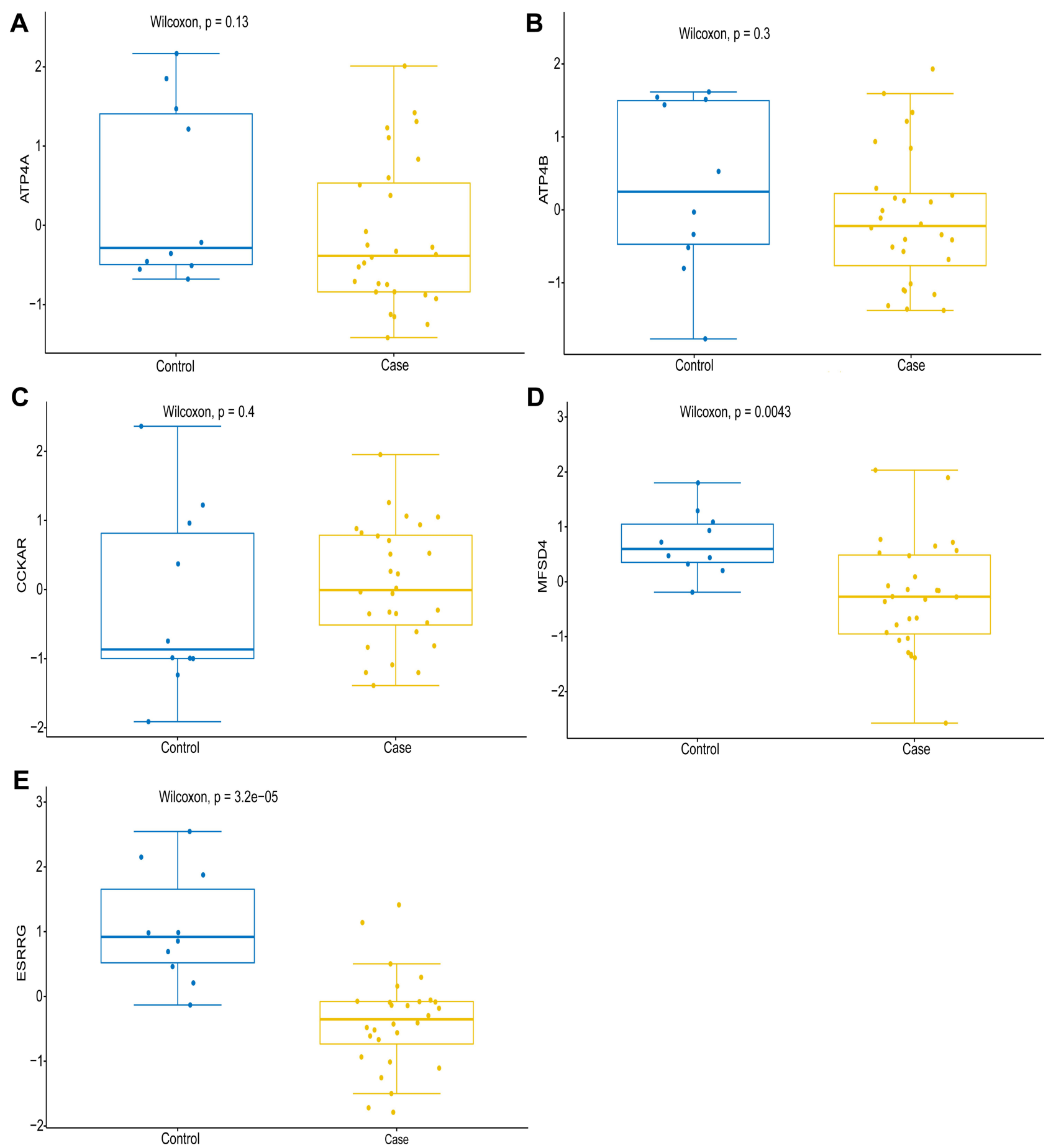

Figure 5 Electronic verification of ATP4A, ATP4B, CCKAR, MFSD4 and ESRRG at the mRNA level. (A) Electronic expression verification of ATP4A; (B) Electronic expression verification of ATP4B; (C) Electronic expression verification of CCKAR; (D) Electronic expression verification of MFSD4; (E) Electronic expression verification of ESRRG. P $<0.05$ was considered to indicate a statistically significant different. Blue color and yellow color represent the control group and the case group, respectively.

This provides a potential direction for further research on the molecular mechanism of esophageal carcinoma.

It has been found that mice lacking estrogen related receptor beta (ESRRB) in heart cells develop dilated cardiomyopathy (DCM) in middle age, leading to defects in calcium processing and cell contractility. ${ }^{37}$ The over expression of ESRRB protein can inhibit the proliferation of prostate cancer cells, revealing the anti-proliferative effect of ESRRB in prostate cancer. ${ }^{38}$ Recent studies have found that the expression of ESRRB protein is missing in breast cancer cells, indicating that ESRRB also plays a tumor suppressor role in breast cancer. ${ }^{39,40}$ 

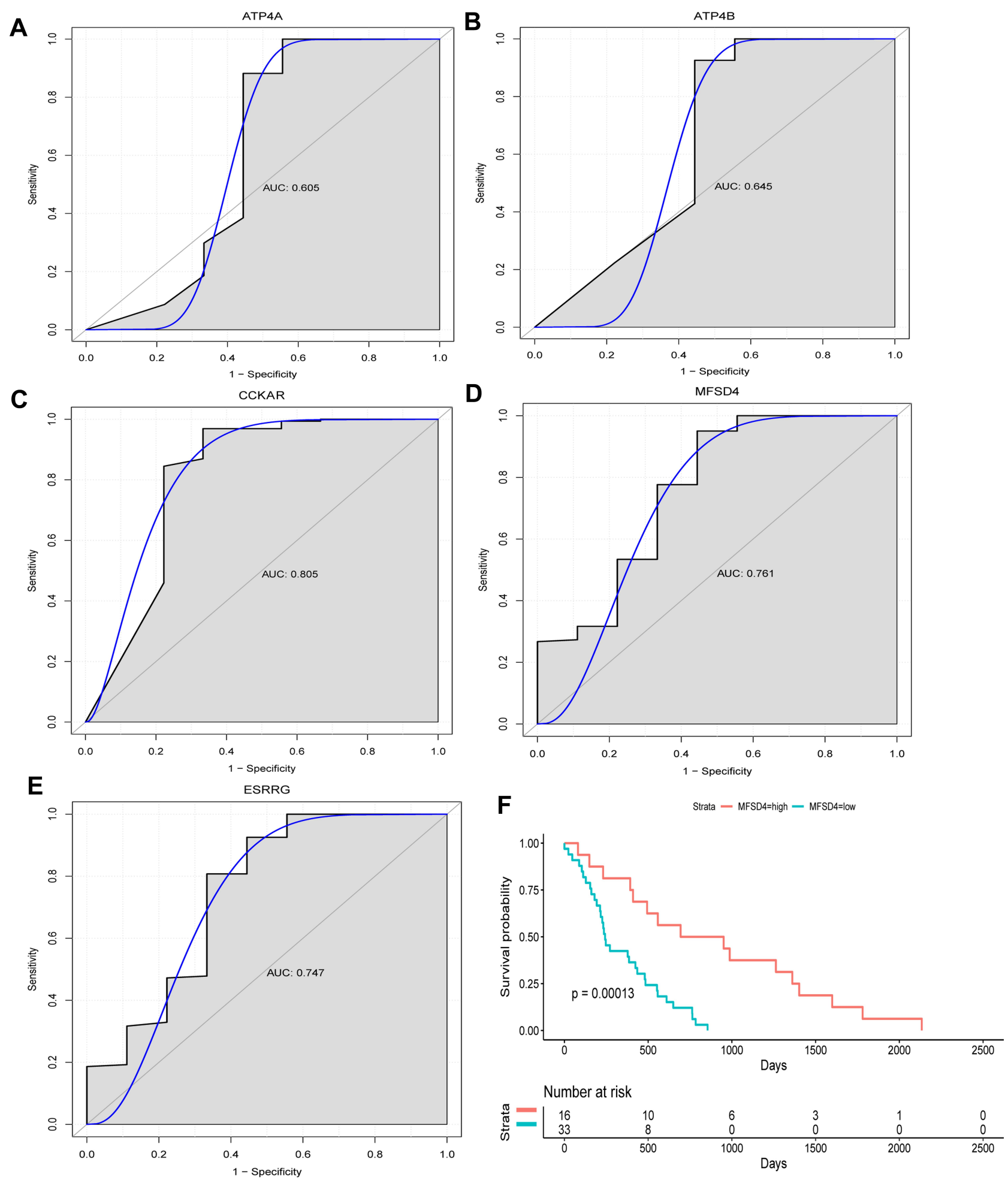

Figure 6 ROC curve of ATP4A, ATP4B, CCKAR, MFSD4, ESRRG (A-E) and prognostic analysis of MFSD4 (F).

Abbreviations: ROC, receiver operating characteristic; AUC, area under curve

In addition, the analysis of exon data from esophagogastric junctional adenocarcinoma revealed mutations in ESRRB, suggesting that ESRRB may be a potential therapeutic target. ${ }^{41}$ Estrogen related receptor gamma
(ESRRG) also encodes a protein similar to estrogen receptors. ${ }^{42}$ Previous studies have shown that ESRRG is a type of tumor suppressor that can inhibit Wingless/ Integrated (Wnt) signaling in gastric cancer. ${ }^{43} \mathrm{~A}$ recent 


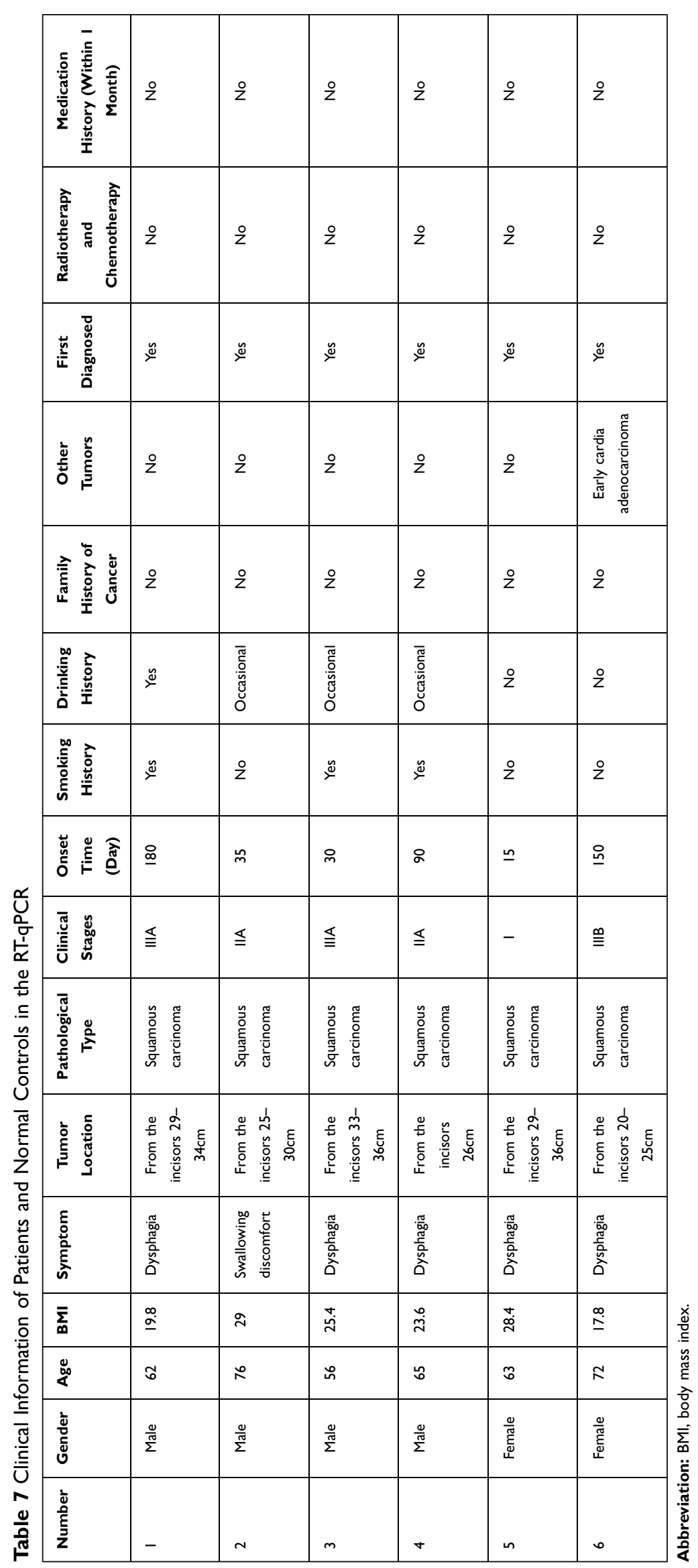


Table 8 Primer Sequences in the RT-qPCR

\begin{tabular}{|c|c|}
\hline Primer Name & Primer Sequence (5' to $\left.3^{\prime}\right)$ \\
\hline GAPDH-F (internal reference) & 5-CTGGGCTACACTGAGCACC-3 \\
\hline GAPDH-R (internal reference) & 5-AAGTGGTCGTTGAGGGCAATG-3 \\
\hline ACTB-F (internal reference) & 5-TCCGCAAAGACCTGTACGC-3 \\
\hline ACTB-R (internal reference) & 5-CTGGAAGGTGGACAGCGAG-3 \\
\hline GPRI55-F & 5-AGCAAAGCTGGACTATTCCCT-3 \\
\hline GPRI55-R & 5-GCCACCAAATAAATGTACTGGA-3 \\
\hline ESRRB-F & 5-GCAGCCCTGAACACCCATT-3 \\
\hline ESRRB-R & 5-AAGGGCGTGGATTGGGGAT-3 \\
\hline ESRRG-F & 5-GCCCTGCCACGAATGAATGT-3 \\
\hline ESRRG-R & 5-TGGGCTGTTCTCCGCATCT-3 \\
\hline CCKAR-F & 5-GTGATCCGCATGCTCATCGT-3 \\
\hline CCKAR-R & 5-TGACGCAGGAGGAGGTGTAG-3 \\
\hline MMPII-F & 5-CCCTGTGAAGGTGAAGGCTC-3 \\
\hline MMPII-R & 5-GATGGCCATGGGTCTCTAGC-3 \\
\hline TPX2-F & 5-ATGGAACTGGAGGGCTTTTTC-3 \\
\hline TPX2-R & 5-TGTTGTCAACTGGTTTCAAAGGT-3 \\
\hline BIRC5-F & 5-AGGACCACCGCATCTCTACAT-3 \\
\hline BIRC5-R & 5-AAGTCTGGCTCGTTCTCAGTG-3 \\
\hline NUF2-F & 5-TGCCTGCCTTCATGTCAGT-3 \\
\hline NUF2-R & 5-GGTCCTCCAAGTTCAGGCTC-3 \\
\hline ANOI-F & 5-GAGAGATCGGTTCCCAGCCT-3 \\
\hline ANOI-R & 5-TGTGACTGTGACCCGGATGT-3 \\
\hline
\end{tabular}

study showed that ESRRG promoter hypermethylation was associated with the occurrence of laryngeal squamous cell carcinoma (LSCC), which suggested that ESRRG can serve as a biomarker for the diagnosis and prognosis of LSCC. ${ }^{44}$ Furthermore, the expression level of ESRRG was found to be reduced in prostate cancer tissues, indicating that ERRG may play an important regulatory role in prostate cancer. ${ }^{45}$ ERRG also plays an essential role in the pathophysiology of breast and endometrial cancer. ${ }^{46,47}$ In the present study, ESRRB and ESRRG were down-regulated in esophageal carcinoma tissues. Furthermore, ESRRB and ESRRG were hypomethylated and hypermethylated, respectively. However, the action mechanism of ESRRB and ESRRG in esophageal carcinoma remains unclear. It was found in the present study that ESRRB and ESRRG were differentially methylated genes, which provides a potential direction for further research on esophageal carcinoma.

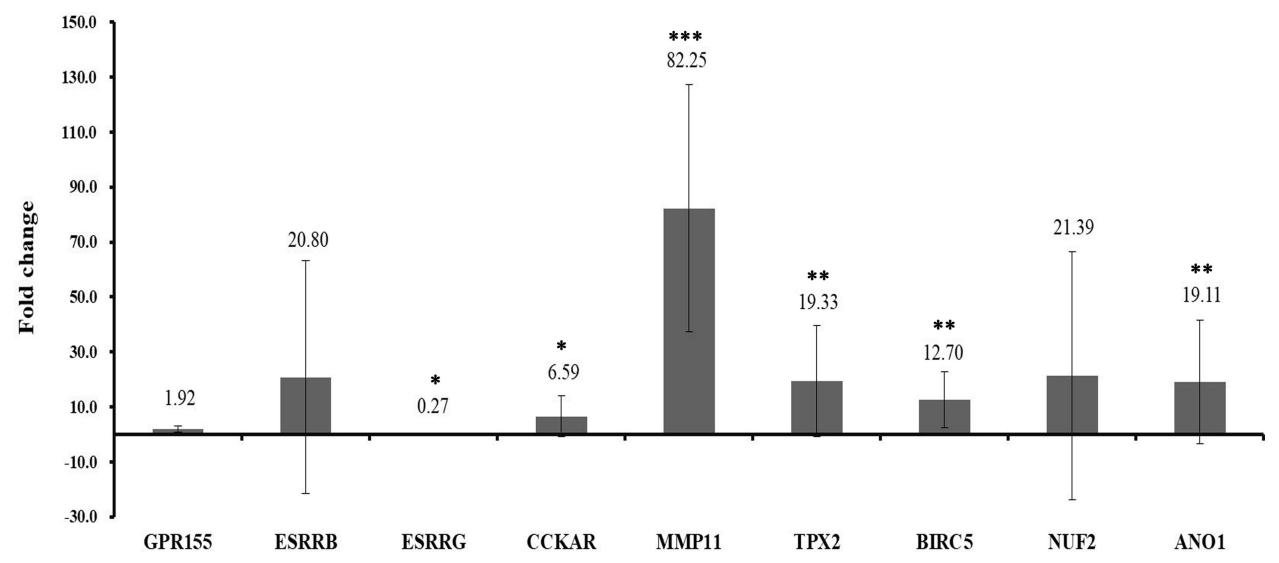

Figure 7 RT-qPCR validation of GPRI55, ESRRB, ESRRG, CCKAR, MMPII, TPX2, BIRC5, NUF2 and ANOI in tissue samples. *Represent $p<0.05$, **Represent $p<0.0$ I, $* * *$ Represent $P<0.001$. $P<0.05$ was considered statistically significant. Fold change $>$ I represent up-regulation, Fold change $<$ I represent down-regulation. $R T-q P C R$, reverse transcription PCR. 


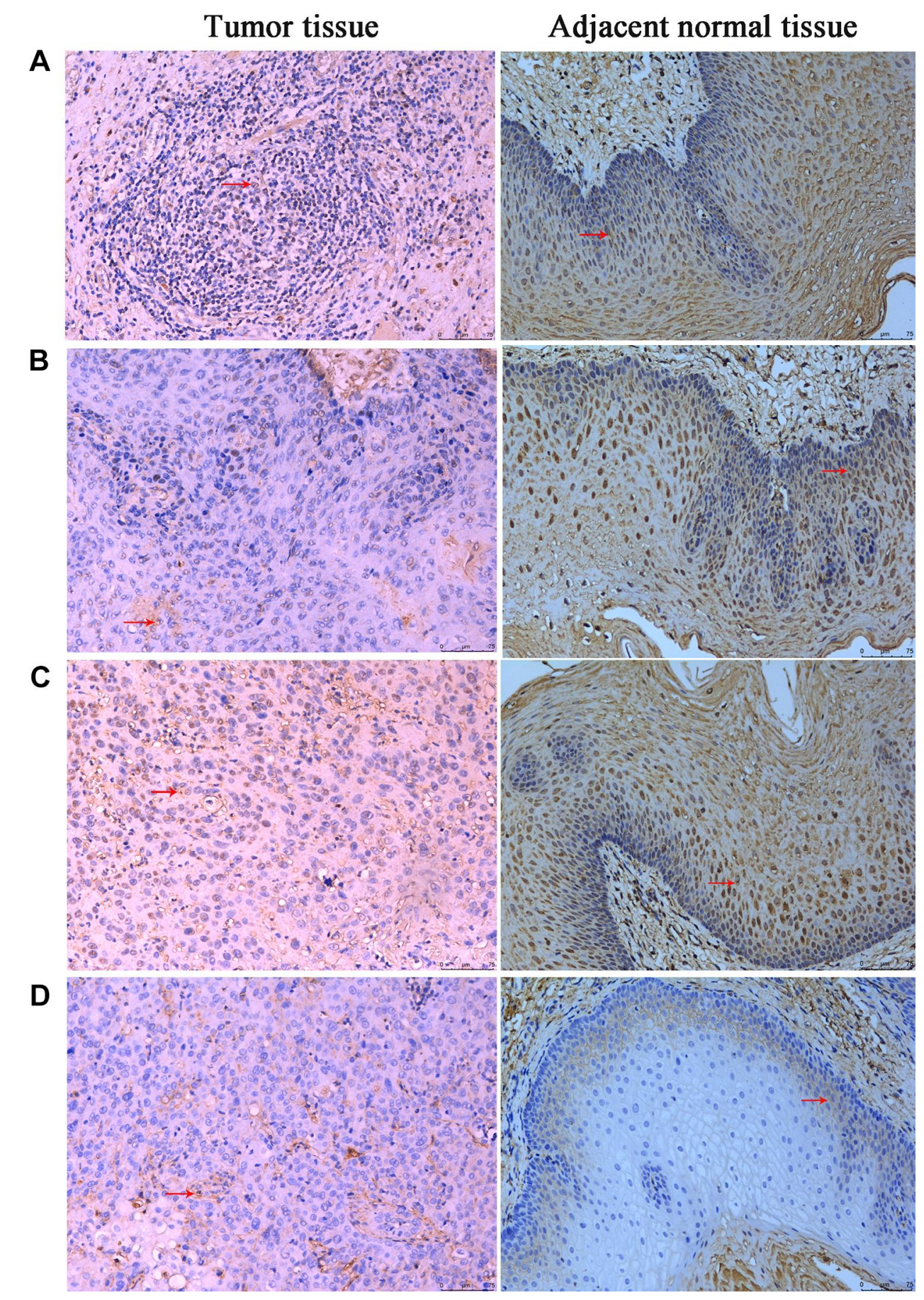

Figure 8 Immunohistochemical analysis of ATP4B (A), B3GATI (B), CCKBR (C) and ESRRG (D). The arrow represents positive ATP4B, B3GATI, CCKBR and ESRRG staining. The length of scale bars in (A-D) was $75 \mu \mathrm{m}$. Magnification, 200x.

In addition to the aforementioned 8 genes, several DEGs, including $G$ protein-coupled receptor 155 (GPR155), matrix metallopeptidase 11 (MMP11), TPX2 microtubule nucleation factor (TPX2), were found to play important regulatory roles in cancer. In a previous study, the mRNA expression of GPR155 was decreased in the hepatocellular carcinoma cell line compared with the control non-cancerous cell line. ${ }^{48}$ A different study showed that the mRNA expression level of MMP11 in pancreatic cancer tissues was significantly higher than that of normal tissues. ${ }^{49}$ In addition, reducing the expression of MMP11 can inhibit tumor growth and the invasion of gastric cancer cells. ${ }^{50}$ Recent research has found that TPX2 is up-regulated in a variety of malignant tumors, 
such as ESCC, ${ }^{51}$ hepatocellular carcinoma, ${ }^{52}$ cervical cancer. ${ }^{53}$ GPR155 was found to be down-regulated, and MMP11 and TPX2 to be up-regulated in esophageal carcinoma. The expression trend was the same as that in other cancer types, which suggests that these three genes may play an important regulatory role in esophageal carcinoma.

The present study had certain limitations. First, the sample size of in vitro verification was too small, which led to a certain degree of error between the validation and bioinformatics analysis results. Thus, future studies with a larger sample size are required. Secondly, the molecular mechanism of the identified genes in esophageal carcinoma remains unclear and should be further studied. In combination, the results of the present study demonstrated that, compared with the paracancerous tissues, ESRRG, MFSD4, CCKBR, ATP4B, ESRRB, ATP4A, CCKAR and B3GAT1 were significantly down-regulated in esophageal carcinoma tissues, suggesting that they may play an essential role in the physiopathology of esophageal carcinoma. The identification of these genes may prove helpful in the development of early diagnosis and treatment options for esophageal carcinoma.

\section{Conclusion}

In the present study, ESRRG, MFSD4, CCKBR, ATP4B, ESRRB, ATP4A, CCKAR and B3GAT1 were differentially methylated genes and DEGs. CCKAR, MFSD4 and ESRRG may serve as diagnostic gene biomarkers in esophageal carcinoma. The high expression level of MFSD4 was significantly correlated with patient survival. Therefore, it was suggested that epigenetic changes of hub genes may play an essential role in esophageal carcinoma. Immunohistochemical analysis showed that the gene expression levels of ATP4B, B3GAT1, CCKBR and ESRRG were decreased in esophageal carcinoma tissues, which was in line with the bioinformatics results. The identified molecular markers may therefore be helpful in the diagnosis and treatment of esophageal carcinoma.

\section{Data Sharing State}

All data generated or analyzed during this study are included in this published article.

\section{Ethics Approval and Consent to Participate}

This study was approved by the ethics committee the Fourth Hospital of Hebei Medical University (NO.2020KY183). All participants were informed as to the purpose of this study, and that this study complied with the Declaration of Helsinki.

\section{Consent for Publication}

All of the authors have agreed to the publication of the work.

\section{Author Contributions}

Conception and design: Y.X. and Z.T.

Execution: Y.X., H.L. and Z.L.

Data analysis and interpretation: N.W., R. L., F.Z. and C.G.

All authors contributed to data analysis, drafting or revising the article, have agreed on the journal to which the article will be submitted, gave final approval of the version to be published, and agree to be accountable for all aspects of the work.

\section{Funding}

The current work was funded by the "Construction of Early Diagnosis and Treatment Platform for Esophageal Carcinoma" Hebei Medical University "Double First Class" Talent Project. The correlations between the expression of long noncoding RNA (SPRY4-1T1) and the lymph node metastasis in esophageal squamous cell carcinoma. Specific project of the National Cancer Center of China on the Scientific Research of Oncology (No. NCC2017A24).

\section{Disclosure}

The authors report no conflicts of interest in this work.

\section{References}

1. Torre LA, Bray F, Siegel RL, Ferlay J. Global cancer statistics, 2012. CA Cancer J Clin. 2015;65:87-108. doi:10.3322/caac.21262

2. Kamangar F, Dores GM, Anderson WF. Patterns of cancer incidence, mortality, and prevalence across five continents: defining priorities to reduce cancer disparities in different geographic regions of the world. $J$ clin oncol. 2006;24:2137-2150. doi:10.1200/JCO.2005.05.2308

3. Cowie A, Noble F, Underwood T. Strategies to improve outcomes in esophageal adenocarcinoma. Expert Rev Anticancer Ther. 2014;14:677-687. doi:10.1586/14737140.2014.895668

4. Probst A, Aust D, Märkl B, Anthuber M, Messmann H. Early esophageal cancer in Europe: endoscopic treatment by endoscopic submucosal dissection. Endoscopy. 2015;47:113-121. doi:10.1055/s-0034-1391086

5. Alsop BR, Sharma P. Esophageal cancer. Gastroenterol Clin North Am. 2016;45:399-412. doi:10.1016/j.gtc.2016.04.001

6. Parry K, Visser E, van Rossum PS, Mohammad NH, Ruurda JP, van Hillegersberg R. Prognosis and treatment after diagnosis of recurrent esophageal carcinoma following esophagectomy with curative intent. Ann Surg Oncol. 2015;22(Suppl 3):S1292-1300. doi:10.1245/s10434015-4840-5 
7. Long L, Pang XX, Lei F, et al. SLC52A3 expression is activated by NF- $\mathrm{kB}$ p65/Rel-B and serves as a prognostic biomarker in esophageal cancer. Cell Mol Life Sci. 2018;75:2643-2661. doi:10.1007/s00018018-2757-4

8. Guo Y, Bao Y, Ma M, et al. Clinical significance of the correlation between PLCE 1 and PRKCA in esophageal inflammation and esophageal carcinoma. Oncotarget. 2017;8:33285-33299. doi:10.18632/ oncotarget. 16635

9. Liu Y, Zhang M, He T, et al. Epigenetic silencing of IGFBPL1 promotes esophageal cancer growth by activating PI3K-AKT signaling.Clin Epigenetics. 2020;12:22.

10. Zhang A, Wang W, Chen Z, et al. SHARPIN inhibits esophageal squamous cell carcinoma progression by modulating hippo signaling. Neoplasia (New York, NY). 2020;22:76-85. doi:10.1016/j. neo.2019.12.001

11. Zhu L, Zhang X, Fu X, et al. TIPE2 suppresses progression and tumorigenesis of esophageal carcinoma via inhibition of the $\mathrm{Wnt} / \beta$ catenin pathway. $J$ Transl Med. 2018;16:7.

12. Kinoshita R, Iwadate M, Umeyama H, Taguchi YH. Genes associated with genotype-specific DNA methylation in squamous cell carcinoma as candidate drug targets. BMC Syst Biol. 2014;8(Suppl 1):S4. doi:10.1186/1752-0509-8-S1-S4

13. Huang J, Wang G, Tang J, et al. DNA methylation status of PAX1 and ZNF582 in esophageal squamous cell carcinoma. Int $J$ Environ Res Public Health. 2017;14. doi:10.3390/ijerph14020216

14. Issa JPJ, Baylin SB, Herman JG. DNA methylation changes in hematologic malignancies: biologic and clinical implications. Leukemia. 1997;11(Suppl 1):S7.

15. Das M, Sharma SK, Sekhon GS, Mahanta J, Phukan RK, Jalan BK. p16 gene silencing along with p53 single-nucleotide polymorphism and risk of esophageal cancer in Northeast India. Tumor Biol. 2017;39(5):1010428317698384. doi:10.1177/1010428317698384

16. Zhou C, Li J, Li Q. CDKN2A methylation in esophageal cancer: a meta-analysis. Oncotarget. 2017;8:50071-50083. doi:10.18632/ oncotarget.18412

17. Qiang Y, Li Q. Intake of dietary one-carbon metabolism-related $\mathrm{B}$ vitamins and the risk of esophageal cancer: a dose-response meta-analysis. Nutrients. 2018;10.

18. Anders S, Huber W. Differential expression analysis for sequence count data. Genome Biol. 2010;11:R106. doi:10.1186/gb-2010-11-10r106

19. Warden CD, Lee H, Tompkins JD, et al. COHCAP: an integrative genomic pipeline for single-nucleotide resolution DNA methylation analysis. Nucleic Acids Res. 2019;47:8335-8336. doi:10.1093/nar/ gkz663

20. Wen J, Yang H, Liu MZ, et al. Gene expression analysis of pretreatment biopsies predicts the pathological response of esophageal squamous cell carcinomas to neo-chemoradiotherapy. Ann Oncol. 2014;25:1769-1774. doi:10.1093/annonc/mdu201

21. Livak KJ, Schmittgen TD. Analysis of relative gene expression data using real-time quantitative PCR and the 2(-Delta Delta $\mathrm{C}(\mathrm{T})$ ) Method. Methods (San Diego, Calif). 2001;25:402-408. doi:10.1006/meth.2001.1262

22. Raja UM, Gopal G, Rajkumar T. Intragenic DNA methylation concomitant with repression of ATP4B and ATP4A gene expression in gastric cancer is a potential serum biomarker. Asian Pacific J Cancer Prevention. 2012;13:5563-5568.

doi:10.7314/ APJCP.2012.13.11.5563

23. Calvete O, Reyes J, Zuñiga S, et al. Exome sequencing identifies ATP4A gene as responsible of an atypical familial type I gastric neuroendocrine tumour. Hum Mol Genet. 2015;24:2914-2922. doi:10.1093/hmg/ddv054

24. Cao D, Zhao D, Jia Z, et al. Reactivation of Atp4a concomitant with intragenic DNA demethylation for cancer inhibition in a gastric cancer model. Life Sci. 2020;242:117214. doi:10.1016/j.lfs.2019.117214
25. Zali MR, Zadeh-Esmaeel MM, Rezaei Tavirani M, Rezaei Tavirani S, Norouzinia M, Rezaei-Tavirani M. Barrett's esophagus network analysis revealed that arginine, alanine, aspartate, glutamate, valine, leucine and isoleucine can be biomarkers. Gastroenterol Hepatol Bed to Bench. 2018;11:S98-s104.

26. Callaghan JM, Tan SS, Khan MA, et al. Renal expression of the gene encoding the gastric $\mathrm{H}(+)-\mathrm{K}(+)$-ATPase beta-subunit. Am J Physiol. 1995;268:F363-374. doi:10.1152/ajprenal.1995.268.3.F363

27. Xu HL, Hsing AW, Vogtmann E, et al. Variants in CCK and CCKAR genes to susceptibility to biliary tract cancers and stones: a population-based study in Shanghai, China. $J$ Gastroenterol Hepatol. 2013;28:1476-1481. doi:10.1111/jgh.12278

28. Miyasaka K, Takata Y, Funakoshi A. Association of cholecystokinin A receptor gene polymorphism with cholelithiasis and the molecular mechanisms of this polymorphism. J Gastroenterol. 2002;37(Suppl 14):102-106. doi:10.1007/BF03326426

29. Chattopadhyay I, Singh A, Phukan R, et al. Genome-wide analysis of chromosomal alterations in patients with esophageal squamous cell carcinoma exposed to tobacco and betel quid from high-risk area in India. Mutat Res. 2010;696:130-138. doi:10.1016/j.mrgentox.2010.01.001

30. Yu B, Lv X, Su L, et al. MiR-148a functions as a tumor suppressor by targeting CCK-BR via Inactivating STAT3 and Akt in human gastric cancer. PLoS One. 2016;11:e0158961. doi:10.1371/journal.pone.0158961

31. Rai R, Kim JJ, Tewari M, Shukla HS. Heterogeneous expression of cholecystokinin and gastrin receptor in stomach and pancreatic cancer: an immunohistochemical study. $J$ Cancer Res Ther. 2016;12:411-416. doi:10.4103/0973-1482.168970

32. Kanda M, Shimizu D, Tanaka H, et al. Metastatic pathway-specific transcriptome analysis identifies MFSD4 as a putative tumor suppressor and biomarker for hepatic metastasis in patients with gastric cancer. Oncotarget. 2016;7(12):13667-13679. doi:10.18632/oncotarget.7269

33. Brown J, Stepien AJ, Willem P. Landscape of copy number aberrations in esophageal squamous cell carcinoma from a high endemic region of South Africa. BMC Cancer. 2020;20:281. doi:10.1186/s12885-020-06788-3

34. Wangerin H, Kristiansen G. CD57 expression in incidental, clinically manifest, and metastatic carcinoma of the prostate. Biomed Res Int. 2014;2014:356427. doi:10.1155/2014/356427

35. Espinosa P, Urra JM. Decreased expression of the CD57 molecule in t lymphocytes of patients with chronic fatigue syndrome. Mol Neurobiol. 2019;56:6581-6585. doi:10.1007/s12035-019-1549-7

36. García-Ayllón MS, Botella-López A, Cuchillo-Ibañez I, et al. HNK-1 carrier glycoproteins are decreased in the alzheimer's disease brain. Mol Neurobiol. 2017;54:188-199. doi:10.1007/s12035-015-9644-x

37. Rowe GC, Asimaki A, Graham EL, et al. Development of dilated cardiomyopathy and impaired calcium homeostasis with cardiacspecific deletion of ESRR $\beta$. Am J Physiol Heart Circ Physiol. 2017;312:H662-h671. doi:10.1152/ajpheart.00446.2016

38. Yu S, Wong YC, Wang XH, et al. Orphan nuclear receptor estrogen-related receptor-beta suppresses in vitro and in vivo growth of prostate cancer cells via 21 (WAF1/CIP1) induction and as a potential therapeutic target in prostate cancer. Oncogene. 2008;27:3313-3328. doi:10.1038/sj.onc. 1210986

39. Sengupta D, Bhargava DK, Dixit A, et al. ERR $\beta$ signalling through FST and BCAS2 inhibits cellular proliferation in breast cancer cells. Br J Cancer. 2014;110:2144-2158. doi:10.1038/bjc.2014.53

40. Madhu Krishna B, Chaudhary S, Mishra DR, et al. Estrogen receptor $\alpha$ dependent regulation of estrogen related receptor $\beta$ and its role in cell cycle in breast cancer. BMC Cancer. 2018;18:607. doi:10.1186/ s12885-018-4528-x

41. Chong IY, Cunningham D, Barber LJ, et al. The genomic landscape of oesophagogastric junctional adenocarcinoma. $J$ Pathol. 2013;231:301-310. doi:10.1002/path.4247

42. Kim JH, Choi YK, Byun JK, et al. Estrogen-related receptor $\gamma$ is upregulated in liver cancer and its inhibition suppresses liver cancer cell proliferation via induction of p21 and p27. Exp Mol Med. 2016;48:e213. doi:10.1038/emm.2015.115 
43. Kang MH, Choi H, Oshima M, Cheong JH, Kim S, Lee JH. Estrogenrelated receptor gamma functions as a tumor suppressor in gastric cancer. Nat Commun. 2018;9:1920.

44. Shen Z, Hu Y, Zhou C. ESRRG promoter hypermethylation as a diagnostic and prognostic biomarker in laryngeal squamous cell carcinoma. J Clin Lab Anal. 2019;33:e22899.

45. Yu S, Wang X, Ng CF, Chen S, Chan FL. ERRgamma suppresses cell proliferation and tumor growth of androgen-sensitive and androgen-insensitive prostate cancer cells and its implication as a therapeutic target for prostate cancer. Cancer Res. 2007;67:4904-4914. doi:10.1158/0008-5472.CAN-06-3855

46. Madhavan S, Gusev Y, Singh S, Riggins RB. ERR $\gamma$ target genes are poor prognostic factors in Tamoxifen-treated breast cancer $J$ Exp Clin Cancer Res. 2015;34:45. doi:10.1186/s13046-0150150-9

47. Yamamoto T, Mori T, Sawada M, et al. Estrogen-related receptor- $\gamma$ regulates estrogen receptor- $\alpha$ responsiveness in uterine endometrial cancer. Int $j$ Gynecol Cancer. 2012;22:1509-1516. doi:10.1097/ IGC.0b013e31826fd623

48. Umeda S, Kanda M, Sugimoto H, et al. Downregulation of GPR155 as a prognostic factor after curative resection of hepatocellular carcinoma. BMC Cancer. 2017;17:610. doi:10.1186/s12885-0173629-2
49. Lee J, Lee J, Kim JH. Identification of matrix metalloproteinase 11 as a prognostic biomarker in pancreatic cancer. Anticancer Res. 2019;39:5963-5971. doi:10.21873/anticanres.13801

50. $\mathrm{Xu} \mathrm{G}$, Zhang $\mathrm{B}$, Ye $\mathrm{J}$, et al. Exosomal miRNA-139 in cancer-associated fibroblasts inhibits gastric cancer progression by repressing MMP11 expression. Int J Biol Sci. 2019;15:2320-2329. doi: $10.7150 /$ ijbs. 33750

51. Liu HC, Zhang Y, Wang XL, et al. Upregulation of the TPX2 gene is associated with enhanced tumor malignance of esophageal squamous cell carcinoma. Biomed Pharmacother. 2013;67(8):751-755. doi:10.1016/j.biopha.2013.04.004

52. Huang DH, Jian J, Li S, Zhang Y, Liu LZ. TPX2 silencing exerts anti-tumor effects on hepatocellular carcinoma by regulating the PI3K/AKT signaling pathway. Int J Mol Med. 2019;44:2113-2122. doi:10.3892/ijmm.2019.4371

53. Song T, Xu A, Zhang Z, et al. CircRNA hsa_circRNA_101996 increases cervical cancer proliferation and invasion through activating TPX2 expression by restraining miR-8075. J Cell Physiol. 2019;234(8):14296-14305. doi:10.1002/jcp.28128

\section{Publish your work in this journal}

OncoTargets and Therapy is an international, peer-reviewed, open access journal focusing on the pathological basis of all cancers, potential targets for therapy and treatment protocols employed to improve the management of cancer patients. The journal also focuses on the impact of management programs and new therapeutic agents and protocols on patient perspectives such as quality of life, adherence and satisfaction. The manuscript management system is completely online and includes a very quick and fair peer-review system, which is all easy to use. Visit http://www.dovepress.com/ testimonials.php to read real quotes from published authors. 